\title{
Irradiation of Dextran and Its Aqueous Solutions With Cobalt-60 Gamma Rays*
}

\author{
Joseph H. Flynn, Leo A. Wall, and William L. Morrow \\ Institute for Materials Research, National Bureau of Standards, Washington, D.C., 20234
}

(October 19, 1966)

\begin{abstract}
Cross-linking predominates over chain scission during the irradiation of concentrated aqueous dextran solutions by cobalt-60 gamma rays in the absence of oxygen. An extensive and long-lived postirradiative viscosity decay, which has not been previously reported, is attributed to the agency of hydrogen peroxide formed during the radiolysis of water. Solid dextran primarily degrades upon $\gamma$-irradiation while dextran triacetate is borderline between dominant scission and cross-linking. Both exhibit a postirradiative viscosity decrease when irradiated in the presence of water vapor. Electron spin resonance spectra of dextran in the solid state and in aqueous solution are presented and compared. Spin resonance spectral and chemical evidence concerning the mechanism of crosslinking and postirradiative decay reactions is presented. There is conflicting evidence for the presence of oxyradicals. Speculations are made concerning possible mechanisms of oxyradical formation and their role in the production of ether and peroxy linkages.
\end{abstract}

Key Words: Aqueous solution, cross-linking, dextran, dextran triacetate, gamma irradiation, polymer degradation postirradiative decay.

\section{Introduction}

The effects of ionizing radiation on dextran have been reported by a number of investigators $[1-7]^{1}$ and dextran has been classed, along with other polysaccharides such as starch and cellulose as a polymer which primarily degrades upon irradiation. One percent solutions of dextran, irradiated with $\gamma$-rays, degraded even more rapidly than dry dextran powder [1] and the irradiation of a concentrated syrupy solution did not produce a gel [1].

Bovey [8] has concluded from the analysis of the effect of high speed electrons on native dextran [2] that the ratio of scissions to cross-links is only slightly greater than two-the critical value above which gel formation will not occur.

This proximity to incipient gelation coupled with the behavior of other polymers suggests that under certain conditions when dextran solutions are irradiated, cross-linking may predominate. For example, solid polyvinyl alcohol, upon irradiation, is degraded in the presence of oxygen [9-10] or in a moderate vacuum [10-12] but is cross-linked in aqueous solution [9] and in the water-swollen state [10].

In this paper, we report the changes in viscosity and osmotic pressure resulting from the $\gamma$-irradiation of solid dextran and dextran triacetate and aqueous solutions of dextran under a variety of conditions.

*Presented at the Division of Cellulose, Wood, and Fiber Chemistry, 148th Am. Chem. Soc. Meeting, Chicago, Ill., September 1964.

Figures in brackets indicate the literature references at the end of this paper.

\section{Experimental Procedure}

The dextran used in these experiments was obtained from Pharmachem Corp. It is a purified dextran from Leuconostoc mesenteroides, NRRL B-512 [viscosity average molecular weight of 109,000; intrinsic viscosity (water at $25{ }^{\circ} \mathrm{C}$ ), $0.33 \mathrm{dl} / \mathrm{g}$; and a number average molecular weight, 28,100 (osmotic pressure)].

Dextran triacetate was prepared by treatment of a formamide solution of the above dextran with pyridine and acetic anhydride [13]. Its intrinsic viscosity in sym-1,1',2,2'-tetrachloroethane at $25{ }^{\circ} \mathrm{C}$ was 0.32 $\mathrm{dl} / \mathrm{g}$.

The solid dextran and dextran triacetate samples were placed in glass ampoules and evacuated to $10^{-5}$ $\mathrm{mm} \mathrm{Hg}$ for several days with occasional heating to $60{ }^{\circ} \mathrm{C}$. The dried, evacuated samples were then sealed off. Dried oxygen at $150 \mathrm{~mm} \mathrm{Hg}$ and/or degassed water vapor were added to other samples before sealing.

The concentrations of dextran and dextran triacetate solutions were calculated from dry weights of these substances by correcting for moisture content.

The dextran solutions were placed in glass ampoules or sealed tube viscometers previously described [14]. The solutions were alternately frozen and refluxed a number of times under vacuum over a period of several days to remove dissolved gases as completely as practicable and then sealed under vacuum. L-shaped pyrex sample tubes were used in the ESR experiments. The empty arm was heated to remove its signal before the sample was transferred to it for the determination of the sample's spectrum. 
The samples were irradiated in a cobalt- 60 gamma facility at $20 \pm 2{ }^{\circ} \mathrm{C}$.

The intrinsic viscosity measurements of the dextran in water and of dextran triacetate in $1,1^{\prime}, 2,2^{\prime}$-tetrachloroethane were performed at $25{ }^{\circ} \mathrm{C}$ in Ubbelohde viscometers. Flow times of the sealed tube viscometers also were measured at $25{ }^{\circ} \mathrm{C}$. Viscosity average molecular weight was calculated from $[\eta]$ $=1 \times 10^{-3} M_{v}{ }^{0.50}$, which has been found to hold for acid-hydrolyzed fractions of NRRL B-512 [15a].

Osmotic pressure determinations were made on water solutions of dextran at $25{ }^{\circ} \mathrm{C}$ in a Bull [15b] osmometer with a Visking dialysis tubing membrane. Extrapolation to infinite dilution from 2.0-0.5 g/dl concentration was performed only on data for the unirradiated dextran so values for $M_{N}$ for irradiated dextrans in tables 3 and 4 were approximated from single points $(0.5 \mathrm{~g} / \mathrm{dl})$ and are included only for drawing qualitative conclusions from them.

Electron spin resonance spectra were obtained for dry evacuated samples and for a water gel on a Varian apparatus with a $100 \mathrm{kHz}$ field modulation at about $1 \mathrm{~mW}$ power and $0.2 \mathrm{G}$ magnetic field modulation.

\section{Results}

Solid dextran was irradiated with cobalt-60 $\gamma$-rays at a dose rate of $0.33 \mathrm{MR} / \mathrm{hr}$ for a total dose of $9.16 \mathrm{MR}$. The storage times between the end of the irradiation and the viscosity determination and the intrinsic viscosities in water at $25^{\circ} \mathrm{C}$ are given in table 1 .

The dry evacuated samples showed least intrinsic viscosity decrease. A slightly greater decrease occurred when oxygen at $150 \mathrm{~mm} \mathrm{Hg}$ was present. The greatest decrease occurred in the samples that were exposed to degassed water vapor at $25^{\circ} \mathrm{C}$ for $30 \mathrm{~min}$. Postirradiative deterioration also was more rapid and more extensive in the presence of water vapor.

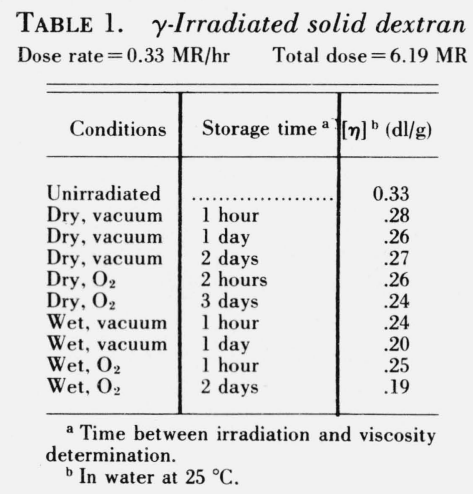

These results in table 1 may be compared with those in table 2 for the irradiation of dextran triacetate. The triacetate was much more resistant to $\gamma$-ray degradation than is dextran. Oxygen enhanced the viscosity decrease as it also did in the case of dextran. Again, there was some evidence for a postirradiative viscosity decay.
TABLE 2. $\gamma$-Irradiated dextran triacetate

\begin{tabular}{|c|c|c|c|}
\hline Conditions & $\begin{array}{c}\text { Total dose } \\
\text { MR }\end{array}$ & Storage time ${ }^{a}$ & {$[\eta]^{\mathrm{b}}(\mathrm{dl} / \mathrm{g})$} \\
\hline $\begin{array}{l}\text { Unirradiated } \\
\text { Dry, vacuum } \\
\text { Dry, vacuum } \\
\text { Dry, vacuum } \\
\text { Dry, } \mathrm{O}_{2} \\
\text { Dry, } \mathrm{O}_{2}\end{array}$ & $\begin{array}{c}0.00 \\
7.92 \\
7.92 \\
25.6 \\
7.92 \\
7.92\end{array}$ & $\begin{array}{l}1 \text { day } \\
8 \text { days } \\
1 \text { day } \\
1 \text { day } \\
60 \text { days }\end{array}$ & $\begin{array}{r}0.32 \\
.34 \\
.33 \\
.32 \\
.31 \\
.27\end{array}$ \\
\hline
\end{tabular}

Reduced specific viscosities, $\frac{\eta_{s p}}{C}$, are plotted as a function of time in figure 1 for 10 percent and 2.75 percent aqueous solutions of dextran in air and vacuum. The sealed viscometers received doses of $\gamma$-rays at intervals A, B, C, D, and E of 1.73, 1.29, $5.73,10.00$ and $8.25 \mathrm{MR}$, respectively, at a dose rate of $0.34 \mathrm{MR} / \mathrm{hr}$. Curves similar to the 2.75 percent solutions were obtained for concentrations of 1 percent and 0.3 percent.

All solutions exhibited a considerable viscosity decrease during the first irradiation interval, A. Augmentation of the reduced viscosity occurred during the latter periods of irradiation (D and E) in all cases in vacuum and in the more concentrated solutions in air. However, gel formation occurred only in the 10 percent solution in vacuum during irradiation period $\mathrm{D}$. The gel softened during storage but was rehardened upon further irradiation (E). Further storage resulted in the slow but complete dissolution of the gel $\left(\frac{\eta_{s p}}{C}=0.317 \mathrm{dl} / \mathrm{g}\right.$ at 148 days $)$ and continued decay to $\eta_{s p} / C=0.282 \mathrm{dl} / \mathrm{g}$ at 192 days.

The broken line in figure 1 represents the decay of an unirradiated 7.5 percent solution of dextran containing $1 M$ hydrogen peroxide.

The postirradiative viscosity decreases for 1 percent dextran solutions irradiated in air and vacuum for total doses of 1.73 and 15.3 MR are shown in figure 2. The viscosity decrease concurrent with irradiation was greater in air than in vacuum but the postirradiative decrease was greater in the evacuated systems. Presence of iron salts decreased the amount of postirraditive degradation in vacuum.

A 10.7 percent dextran solution, irradiated at a 28fold higher dose rate $(9.54 \mathrm{MR} / \mathrm{hr})$ for a total dose of 19.08 MR did not form a gel. The intrinsic viscosity of the dextran changed from an initial value of 0.33 to $0.27 \mathrm{dl} / \mathrm{g}$ (in air) and to 0.23 in vacuum.

It may be concluded from the above results that the conditions conducive to gelation are high concentration, exclusion of air and a dose rate somewhat less than $10 \mathrm{MR} / \mathrm{hr}$.

Irradiation of an evacuated dextran-water paste at $0.33 \mathrm{MR} / \mathrm{hr}$ for a total dose of 9.61 MR resulted in an insoluble material and a sol fraction of 0.23 . The material had the same physical appearance as, for 


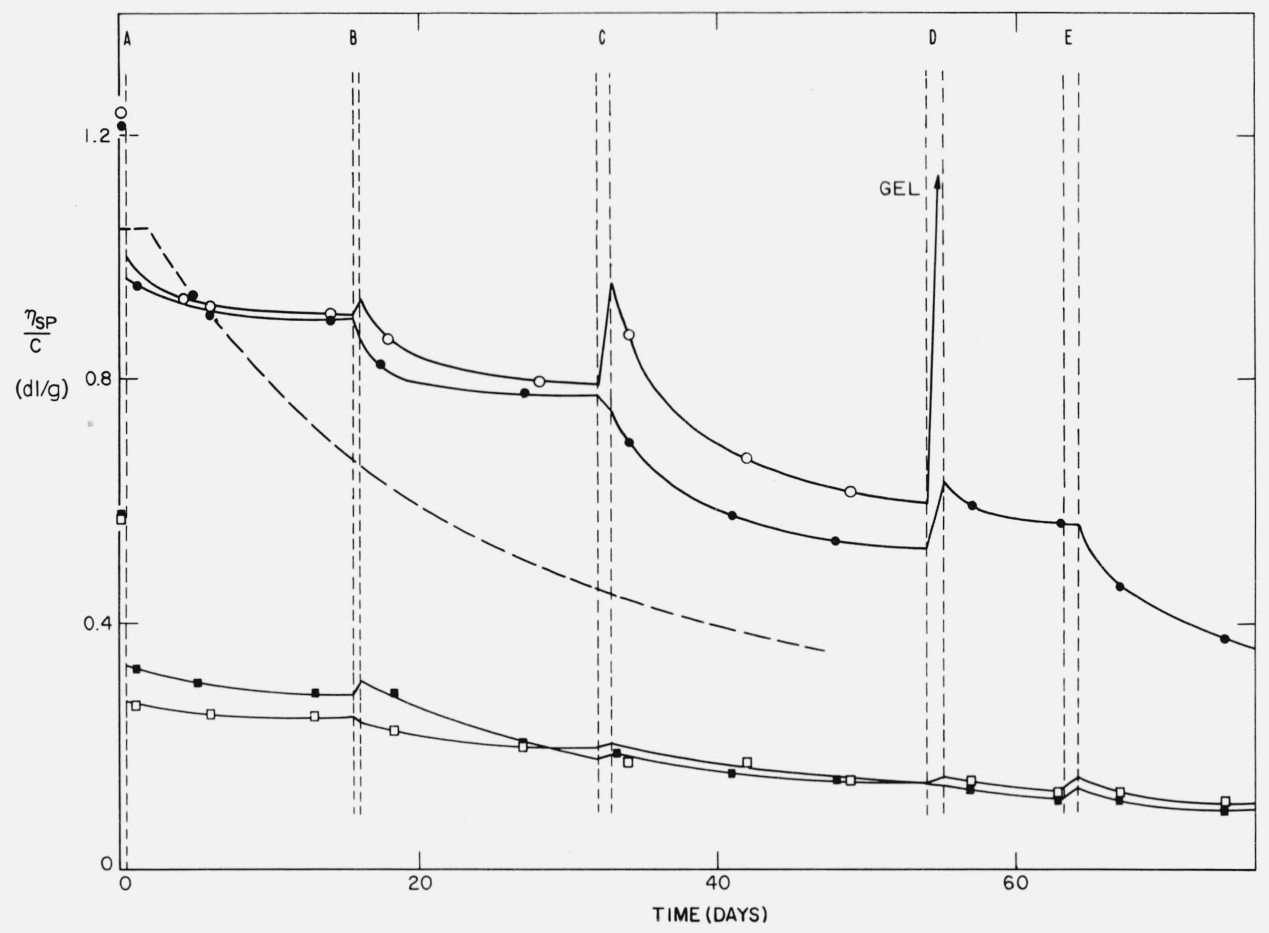

FIGURE 1. Viscosities of intermittently irradiated aqueous dextran solutions.

Rate of irradiation, $0.34 \mathrm{MR} / \mathrm{hr}$. Total dose during irradiation intervals $\mathrm{A}, \mathrm{B}, \mathrm{C}, \mathrm{D}$, and $\mathrm{E}$ are $1.73,1.29,5.73,10.0$, and 8.25 MR, respectively.

$9.93 \%$, vacuum

- $9.87 \%$, air

$2.75 \%$, vacuum

$2.75 \%$, air

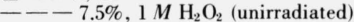

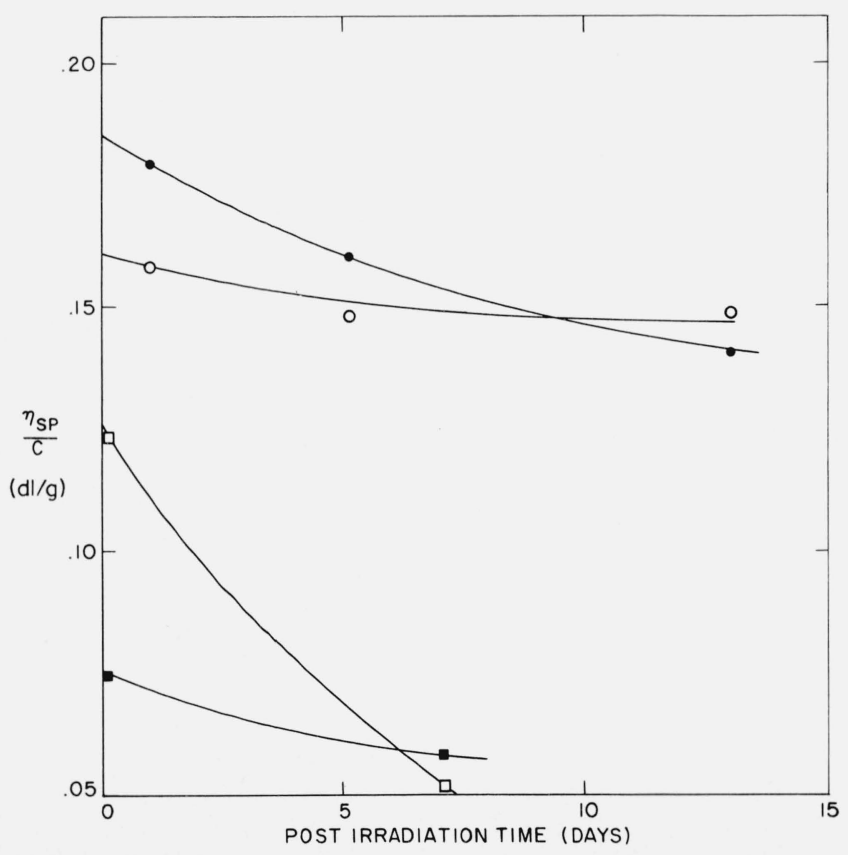

Figure 2. Postirradiative viscosity decay of 1 percent aqueous dextran solutions.

Rate of irradiation, $0.34 \mathrm{MR} / \mathrm{hr}$. Initial $\eta_{s, \nu} / \mathrm{c}, 0.42 \mathrm{dl} / \mathrm{g}$.

vacuum, $1.73 \mathrm{MR}$

air, $1.73 \mathrm{MR}$

vacuum, $15.3 \mathrm{MR}$

air, 15.3 MR. example, cross-linked dextran prepared by heating dry dextran swollen in dimethyl formamide with epichlorohydrin and sodium hydroxide. Similar experiments with a glycerine-dextran paste and a 15 percent solution of dextran in glycerine did not produce any gel.

The intrinsic viscosity and number average molecular weight (from osmotic pressure) are given as a function of storage time in table 3 for a 19.1 percent solution of dextran irradiated at a rate of $0.33 \mathrm{MR} / \mathrm{hr}$ for a total dose of 21.45 MR. Here, the intrinsic viscosity increased upon irradiation while the number average molecular weight showed a slight decrease.

The number average molecular weights of two of the dextran solutions shown in figure 1 are given in table 4. The overall degradation was less in the more concentrated solution.

TABLE 3. Number average molecular weight and intrinsic viscosity at $25^{\circ} \mathrm{C}$ of $19.1 \%$ dextran in water irradiated under vacuum Dose rate $=0.33 \mathrm{MR} / \mathrm{hr}$ Total dose $=21.45 \mathrm{MR}$

\begin{tabular}{l|r|r}
\hline \hline & $M_{N}{ }^{\mathrm{a}}$ & {$[\eta]^{\mathrm{b}}(\mathrm{dl} / \mathrm{g})$} \\
\hline Before irradiation & 28,100 & 0.33 \\
Immediately after & 24.100 & .40 \\
4 Days after & 14.700 & .36 \\
24 Days after & 13.200 & .31 \\
\hline \multicolumn{2}{|c}{} \\
\hline
\end{tabular}

' In water at $25{ }^{\circ} \mathrm{C}$. 
TABLE 4. Number average molecular weight of irradiated dextran solutions

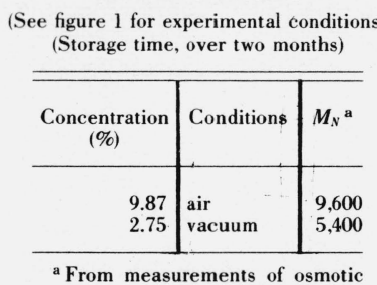
pressure, in water, $25^{\circ} \mathrm{C}$.

The electron spin resonance spectrum for dry dextran irradiated in a vacuum at a dose rate of $9.02 \mathrm{MR} / \mathrm{hr}$ for a total dose of $14.58 \mathrm{MR}$ is shown in figure $3 \mathrm{~b}$. The general shape of the spectrum did not change upon several months' storage at room temperature. This spectrum may be compared with that in figure $3 \mathrm{a}$ obtained from dextran plus hydroxyl radical generated from titanous ion and hydrogen peroxide in an aqueous flow system [16].

A gel, formed by the irradiation of a concentrated dextran solution at a rate of $9.02 \mathrm{MR} / \mathrm{hr}$ for $1 / 2 \mathrm{hr}$ in vacuum, gave no signal a few minutes after irradiation. This indicates that if radicals were present their concentration was less than $10^{-8} \mathrm{~mol} /$ liter.

\section{Discussion}

An increase in polydispersity and branching upon irradiation has been found both for solid dextran [6] and for aqueous solutions [3]; e.g., see table 3, where an increase in $[\eta]$ concurrent with a slight $\bar{M}_{N}$ decrease for the 19.1 percent solution demonstrates this observation. This suggests a near balance between scission and cross-linking in both cases. Because of these structural changes, no effort was made to convert viscosity values to molecular weights.

The postirradiative decay in solid dextran (table 1) and especially in solution (fig. 1) has not been taken into account by previous investigators and could materially affect many of their results and conclusions.

The calculated radical concentration in solid irradiated dextran [7] is of the same order of magnitude as the calculated chain scissions during the postirradiative decay. Therefore, much of this decay in the dry solid may be attributed to long-lived radicals. This decrease in degree of polymerization with time can result from the slow decay of radicals either by directly causing scission or by the production of waterlabile linkages, or from the decrease in concentration of radicals potentially able to cross-link upon solution of the dextran. Hydrogen is evolved during the $\gamma$-irradiation of solid dextran $[4,7]$ so cross-linkingtype radicals may be present in a steady-state concentration waiting to be unleashed by dissolution.

The above explanations are all compatible with the enhancement of postdecay by oxygen. Traces of water have little observable effect during irradiation, but cause a marked postirradiative viscosity decrease.
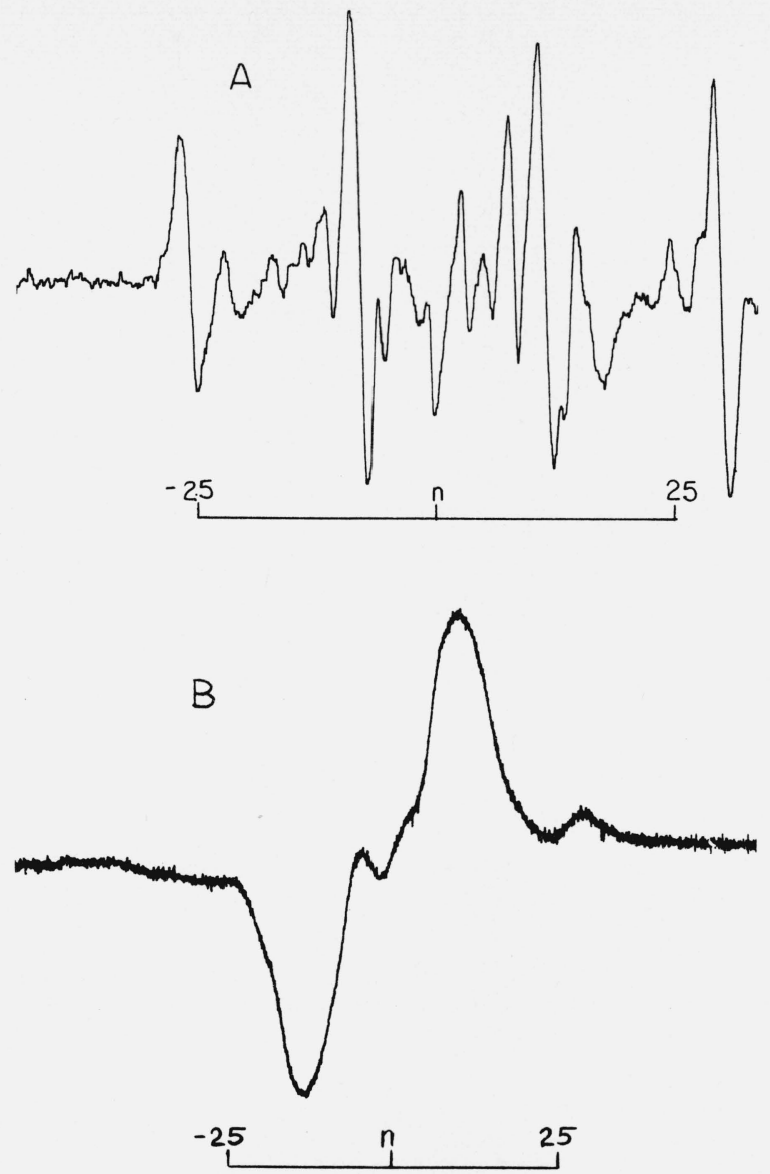

FIGURE 3. The ESR spectra for $\gamma$-irradiated dextran. (a) Aqueous flow system-dextran plus hydroxyl radicals $\left(\mathrm{Ti}^{3+}\right.$ and $\mathrm{H}_{2} \mathrm{O}_{2}$ ). (Ref. [16]). (b) Dry-evacuated dextran; field increases to right.

This is attributed to the same reaction which causes a similar effect in solution.

The intrinsic viscosities for irradiated solid dextran triacetate in table 2 indicate a greater preponderance of cross-linking than is the case for solid dextran, although gelation did not occur under these conditions. It may be predicted that longer aliphatic esters will further augment cross-linking as the polymer side chains become more polyolefin-like in character.

The differential electron spin resonance spectrum shown in figure $3 \mathrm{~b}$ for irradiated solid dextran is almost identical with that observed by Kinell at room temperature [7]. It contains mainly a poorly resolved doublet of about $15 \mathrm{G}$ separation. Satellite structure and other complicating features indicate that several radical species are present.

A single fracture of each of the 22 bonds per dextran anhydroglucose unit would produce 44 radical species, viz, $10 \mathrm{H}, 3 \mathrm{OH}, 7$ oxy-radicals $(\geqslant \mathrm{C}-\mathrm{O} \cdot), 1 \beta$ 
hydro-radical $(-\underset{\mid}{\dot{\mathrm{C}}}-\underset{\mathrm{C}}{\mathrm{H}}-), 1 \quad \beta, \beta, \beta^{\prime}$ trihydro-radical $\left(\begin{array}{ccc}\stackrel{\mathrm{C}}{\mathrm{C}}-\dot{\mathrm{C}}-\mathrm{C} \\ -\mathrm{C}- \\ \mathrm{H} & \mid & \mathrm{H}\end{array}\right), \quad 1 \quad \alpha, \alpha^{\prime}$ dihydro-radical $\left(\begin{array}{c}\mathrm{H} \\ -\mathrm{C} \cdot \\ \mathrm{H}\end{array}\right), 1$ $\alpha, \alpha, \beta$ trihydro-radical $\left(\begin{array}{rr}\mathrm{H} & \mathrm{H} \\ -\mathrm{C}-\mathrm{C} & \mathrm{H}\end{array}\right), 3 \beta, \beta^{\prime}$ dihydro-

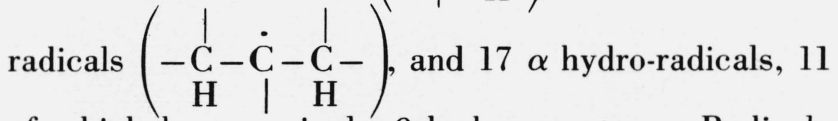
of which have a single $\beta$ hydrogen atom. Radicals formed by disproportionation and from ionic precursors may be added to these possibilities. Therefore, it is not surprising that the spectrum is ill-defined and appears to be a composite.

The "most probable" primary radical, $(\underset{\mid \mathrm{H}}{\mathrm{C}}-\underset{\mathrm{C}}{\mathrm{H}}-\stackrel{\mid}{\mathrm{C}}-\mathbf{|})$, which should produce a four-line hyperfine split doublet, certainly does not dominate the spectrum. Kinell [7] attributes the spectrum to be mainly that of a single hydrogen with negligible interaction with $\beta$ hydrogen as he interprets the smearing out of the structure at shorter wavelengths to be the result of a direct field effect. The ESR spectrum of $\gamma$-irradiated cellulose has many similar features [17]. The greater splitting found in highly oriented ramie cellulose [17] also suggests $\alpha$ hydrogen interaction.

An oxy-radical interacting strongly with a nearby proton would be expected to produce a broad symmetrical doublet and would have the thermal and oxidative stability found experimentally. Other evidence for such a radical is given in the subsequent discussion of irradiation in solution.

The electron spin resonance spectrum for dextran plus hydroxyl radicals in aqueous solution [16] is given in figure $3 \mathrm{a}$. It is considered here because much of the reaction upon irradiation in dilute aqueous solution will be dextran interacting with $\mathrm{OH}, \mathrm{H}, \mathrm{O}_{2} \mathrm{H}$, etc., produced during the radiolysis of water. The spectrum is quite complicated and the lack of overall symmetry suggests that at least several radicals are present. The four principal lines have approximately 1,2,2,1 intensities and a $19 \mathrm{G}$ splitting compatible with radicals of the type,

$-\stackrel{C}{-}-\dot{C}-\stackrel{C}{C}-$. However, reactions such as, ROH $\mathrm{H} \quad \mathrm{H} \quad \mathrm{H}$

$+\mathrm{OH} \longrightarrow \mathrm{R}+\mathrm{H}_{2} \mathrm{O}+\mathrm{O}$, are not as energetically favored as simple hydrogen abstraction from a secondary carbon atom. There is no good evidence for the spectrum predicted for radicals of the type<smiles>CC(C)C(C)C</smiles>

The effect of $\gamma$-irradiation on aqueous solutions of polymers such as polyvinyl alcohol, polyethylene oxide, polypyrrolidine, etc., have been investigated in detail by Charlesby [18] and Sakurada [19]. These polymers have a minimum gelation dose at around 1 percent concentration which is not far above the critical concentration for gel formation. Dextran, on the other hand, degrades less rapidly in more concentrated solution. (See table 4.)

This anomalous behavior of $\gamma$-irradiated polysaccharide solutions may be explained by two separate effects. The first, a rapid postirradiative depolymerization reaction, will be discussed subsequently. The second concerns differences in the cross-linking process and its explanations are more speculative.

Cross-linking in aqueous solutions of polyvinyl alcohol, for example, is assumed to occur by hydrogen abstraction followed by $2 R \longrightarrow R-R[18,19]$. " (For dry samples of PV.A, irradiated in air or vacuum, there is some evidence to the contrary. Periodate oxidation brings all samples to the same limiting DP, irrespective of dose, indicating that scission and cross-linking may occur mainly at 1,2 glycol groups [20].)

For dextran, cross-links of the type,

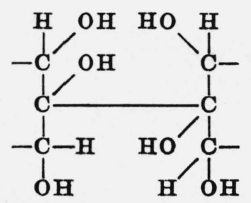

would be prohibitively restrictive sterically, so, unless pendant decyclitized anhydroglucose fragments are involved, the probable modes of connection are ether and/or peroxy linkages.

Thus, if the reaction in eq (1) can not occur, eqs $(2-5)$ produce unstable peroxy links while eqs $(6,7)$ produce stable ether linkages.

$$
\begin{gathered}
\mathrm{R} \cdot+\mathrm{R} \cdot \longrightarrow \mathrm{R}-\mathrm{R} \\
\mathrm{R}+\mathrm{O}_{2} \longrightarrow \mathrm{RO}_{2} \\
\mathrm{RO}_{2}+\mathrm{R} \longrightarrow \mathrm{ROOR} \\
\mathrm{RO}_{2}+\mathrm{RO}_{2} \longrightarrow \mathrm{ROOR}+\mathrm{O}_{2} \\
\mathrm{RO}+\mathrm{RO} \longrightarrow \mathrm{ROOR} \\
\mathrm{RO}+\mathrm{R} \longrightarrow \mathrm{ROR} \\
\mathrm{RO}+\mathrm{RO} \longrightarrow \mathrm{ROR}+\mathrm{O}
\end{gathered}
$$

Therefore, if ether links are formed, oxy-radicals must be present in the solution. If eq (6) represents the cross-linking mechanism, then $R \cdot$ must simultaneously be present. Equation (2) would then explain the inhibition of cross-linking by oxygen which occurs here and in the $\gamma$-initiated polymerization of glucose [21].

Possible sources of alkoxy radicals are the dissociation of peroxides [eq (8)] and disproportionation between $\mathrm{R}$ and $\mathrm{O}_{2} \mathrm{H}$ radicals [eq $(9)$ ]. 


$$
\begin{gathered}
\mathrm{ROOR} \longrightarrow 2 \mathrm{RO} \\
\mathrm{R}+\mathrm{O}_{2} \mathrm{H} \longrightarrow \mathrm{RO}+\mathrm{OH}
\end{gathered}
$$

Since cross-linking is dominant only at high concentrations the main source of RO may be the direct radiolysis of dextran. In dilute solutions the $\mathrm{RO} \cdot$ concentration should be diminished by the presence of $\mathrm{OH}$ which may either combine or disproportionate with it.

$$
\mathrm{RO}+\mathrm{OH}\} \longrightarrow \mathrm{ROOH}
$$

Another mechanism of RO formation has been proposed by Grishina [22]. He concludes from the changes in the ESR spectrum of $\gamma$-irradiated solid $\mathrm{PVA}$ that $\mathrm{HO}-\mathrm{C} \cdot \mathrm{HCO} \cdot \mathrm{H}_{\mid} \cdot$ takes place at room temperature. (Such a rearrangement can explain the formation of deuterium containing hydrocarbon fragments [23] and the absence of $D_{2}$ in the evolved gases during the photolysis [23] and radiolysis [24] of cellulose containing OD groups.)

This rearrangement could occur either through an inter- or intra-molecular transfer,

$$
\begin{aligned}
& \underset{\mathrm{H}-\mathrm{C}}{\mathrm{C}} \mathrm{OH}+\underset{\xi}{\stackrel{\mathrm{C}}{\mathrm{j}}-\mathrm{OH}} \rightleftharpoons \underset{\xi}{\mathrm{H}-\underset{\mathrm{C}}{\mathrm{C}}-\mathrm{O} \cdot \mathrm{H}-\underset{\xi}{\mathrm{C}}-\mathrm{OH}} \rightleftharpoons \\
& \underset{\xi}{\mathrm{H}-\mathrm{C}}-\mathrm{O} \cdot+\underset{\xi}{\mathrm{H}-\mathrm{C}}-\mathrm{OH}
\end{aligned}
$$

or in acid solution through a proton exchange reaction. Sugar solutions [25] and dextran solutions [5] show a marked increase in acidity $(p \mathrm{H} \longrightarrow 3)$ upon $\gamma$-irradiation.

Bonder et al., [21] find no indication of $\mathrm{C}-\mathrm{D}$ bond formation from infrared investigation of the polymer formed during the irradiation of 0.1 percent glucose solutions in heavy water. Apparently the transfer reaction in eq (11) does not take place in dilute solution.

Kuri [26] points out the remarkable inertness to air and scavenger gases of radicals formed from polyhydroxy solids. Hydrogen-bonded alkoxy-radicals as in eq (11) should show such inertness. However Kinell [7] can find no evidence of deuteron-electron interaction in the ESR spectrum of $\gamma$-irradiated heavywater-treated dextran.

Although the agency of oxy-radicals certainly has not been established, one of the many possible ether links formed by eq (6), a 3-6 link, is shown below.

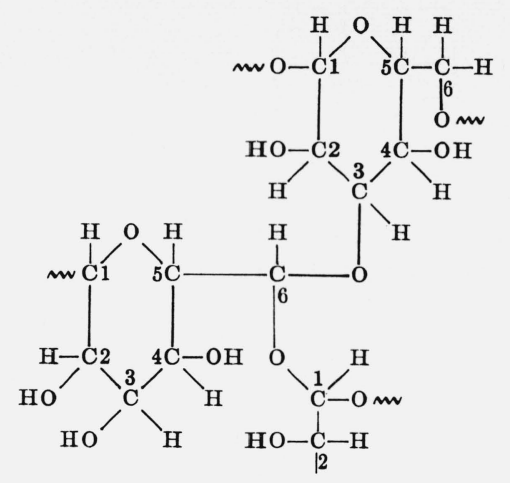

Equations (2-5) result in the formation of peroxy cross-links. The extreme lability of cross-links formed in aqueous solution as seen from the initial rapid viscosity decay in figure 1 and in table 3 suggests such a possibility. Comparison of the postirradiative decay of solutions in air and vacuum in figure 2 again points to the rapid deterioration of the cross-links formed in the evacuated solution. Although the viscosity decreases less in vacuum due, presumably, to concurrent cross-linking, both solutions tend toward the same ultimate viscosity upon storage.

The principle branching points in native dextran are 1,3 and 1,4-like linkages. If similar types of crosslinks form in the irradiated dextran then a loose network with one or more anhydroglucose units in the connecting links would result. The 1,3 and 1,4 linkages in native dextran are more susceptible to acid hydrolysis than the normal 1,6 links [27]. However, free radical initiated cross-linking can not have the same formative mechanism as natural branching which is presumably a condensation process.

The production of three carbon atom dihydroxy acetone (from glyceraldehyde), two carbon atom glyoxal and four carbon atom erythrose from the $\gamma$-irradiation of glucose or dextran in dilute solution [5] suggests that hydrogen abstraction at the 2,3, and 4-carbon atoms can result in scission plus carbonyl formation. These pendant side-chains could be the mode of cross-linking. Of the nine carbon-carbon-ether links, primary scission of four produce pendant groups; two, ring opening with greater geometrical flexibility and only the remaining three result directly in chain fracture.

We attribute the postirradiative decay of viscosity to the presence of hydrogen peroxide, the only longlived product of the radiolysis capable of initiating further degradation. The viscosity decay of a 7.5 percent solution of dextran containing $1 M$ hydrogen peroxide, in figure 1 , is similar to the postirradiative decay at comparable reduced viscosities.

Hydrogen peroxide is formed during the radiolysis of water and its production is augmented by the presence of carbohydrates in the solution [4,25]. Hydrogen peroxide is formed at an initial rate corresponding to $\mathrm{G}\left(\mathrm{H}_{2} \mathrm{O}_{2}\right)=1.8$ during the $\gamma$-irradiation of 0.19 percent aqueous dextran solution in oxygen and a slow postirradiative disappearance of the $\mathrm{H}_{2} \mathrm{O}_{2}$, not found when pure water has been irradiated, has been observed [5]. 
The marked lowering of viscosity of dextran and other polysaccharide solutions by very dilute hydrogen peroxide [28] has been classified as a hydrolysis reaction as shorter chain polysaccharides rather than oxidized products are formed [28].

The- mechanism by which $\mathrm{H}_{2} \mathrm{O}_{2}$ catalyzes this nonoxidative cleavage is not established. Hydrogen peroxide is far too weak an acid for the likelyhood of an acid catalyzed hydrolysis. Likewise, it is difficult to envision a direct molecular attack by $\mathrm{H}_{2} \mathrm{O}_{2}$ which would not produce an oxidized product probably through some hydroperoxy intermediate.

Active species formed during the slow decomposition of $\mathrm{H}_{2} \mathrm{O}_{2}$ are probably responsible for the dextran cleavage. If $\mathrm{OH}$ radicals are formed in the initiation step, then the simplest chain mechanism for $\mathrm{H}_{2} \mathrm{O}_{2}$ decomposition is [29]

$$
\begin{gathered}
\mathrm{OH}+\mathrm{H}_{2} \mathrm{O}_{2} \longrightarrow \mathrm{H}_{2} \mathrm{O}+\mathrm{HO}_{2} \\
\mathrm{HO}_{2}+\mathrm{H}_{2} \mathrm{O}_{2} \longrightarrow \mathrm{H}_{2} \mathrm{O}+\mathrm{O}_{2}+\mathrm{OH}
\end{gathered}
$$

eventually followed by second order termination by radical disproportionation or combination [29].

Dextran will compete with $\mathrm{H}_{2} \mathrm{O}_{2}$ for the $\mathrm{OH}$ radicals, eq (14)

$$
\underset{\xi}{\mathrm{H}} \underset{\mathrm{C}}{\xi} \mathrm{OH}+\mathrm{OH} \longrightarrow \underset{\xi}{\stackrel{\mathrm{C}}{\mathrm{O}}} \underset{\mathrm{OH}}{\mathrm{H}}+\mathrm{H}_{2} \mathrm{O}
$$

but the more sluggish dextran radicals may contribute more to the depropagation reaction as in eq (15),

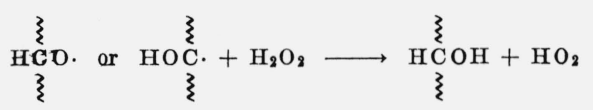

than to second order termination reactions, thus catalyzing the $\mathrm{H}_{2} \mathrm{O}_{2}$ decomposition. Also the reaction of dextran radicals with $\mathrm{OH}$ will not generally lead to stable chain-terminating products, e.g.,

$$
\begin{aligned}
\mathrm{RO}+\mathrm{OH} & \rightleftharpoons \mathrm{ROOH} \\
& \rightarrow \mathrm{ROH}+\mathrm{O} .
\end{aligned}
$$

Only estimates of the scission to cross-link ratio may be made as it is impossible to separate completely the viscosity change resulting from the postirradiative decomposition reaction from the scission and crosslinking occurring as a more immediate consequence of the $\gamma$-irradiation. However, the initial viscosity decrease for the 10 percent solution in vacuum in figure 1 indicates that the scission to cross-link ratio is greater than one [30] but less than two, the critical value above which gelation will not occur.
The low sol fraction of 0.23 for the evacuated waterdextran paste irradiated for a total dose of 9.61 MR suggests a ratio of scissions to cross-links of less than one for these conditions.

The authors thank R. E. Florin for his assistance in obtaining and advise in interpeting the electron spin resonance spectra.

\section{References}

[1] C. R. Ricketts and C. E. Rowe, Chem. Ind. (London), 46 (1951).

[2] F. P. Price, W. D. Bellamy, and E. J. Lawton, J. Phys. Chem. 58, 821 (1954).

[3] R. Lang, E. S. Schmitt, E. J. Henley, and E. L. Gaden, U.S. AEC Rept. NY03320 (Part II) 50 (1956).

[4] G. Binder and A. Vincze, Magyar Tudományos Akad. Központi Fiz. Kutató Intézetének Közle-ményei 5, 364 (1957).

[5] G. O. Phillips and G. J. Moody, J. Chem. Soc. 3534 (1958)

[6] K. A. Granath and P.-O. Kinell, Acta. Chemica Scandinavica 15, 141 (1961).

[7] P.-O. Kinell, A. Lund, and T. Vänngård, Arkiv för Kemi 23, 193 (1965).

[8] F. A. Bovey, The Effects of Ionizing Radiation on Natural and Synthetic High Polymers (Interscience, New York, 1958), pp. 197-203.

[9] P. Alexander and A. Charlesby, J. Chim. Phys. 52, 691 (1955).

[10] K. Shinohara et al., Dai-2 kai Nippon Isotope Kaigi Hobunshu, p. 142 (1958); Proc. Inter. Conf. Peaceful Uses At. Energy, Geneva 29, 186 (1958).

[11] A. Danno, J. Phys. Soc. Japan 13,614 (1958).

[12] I. Sakurada and S. Matsuzawa, Kobunshi Kagaku 17,268 (1960).

[13] A. Jeanes and C. A. Wilham, J. Am. Chem. Soc. 68, 742 (1946).

[14] L. A. Wall and M. Magat, J. Chim. Phys. 50, 308 (1953).

[15a] M. Wales, P. A. Marshall, and S. G. Weissberg, J. Polymer Sci. 10, 229 (1953); F. R. Senti, N. N. Hellman, N. H. Ludwig, G. E. Babcock, R. Tobin, C. A. Glass, and B. L. Lamberts, J. Polymer Sci. 17,527 (1955).

[15b] H. B. Bull and B. T. Currie, J. Am. Chem. Soc. 68, 742 (1946).

[16] F. Sicilio and R. E. Florin, private communication.

[17] R. E. Florin and L. A. Wall, J. Polymer Sci. 1A, 1163 (1963).

[18] A. Charlesby and P. Alexander, J. Polymer Sci. 23, 355 (1957).

[19] I. Sakurada and Y. Ikada, Bul. Inst. Chem. Research Kyoto Univ. 39, 99 (1961); 40, 1, 16, 25 (1962); 41, 103, 114, 123 (1963).

[20] Y. Hirano, Bul. Chem. Soc. Japan 34, 292 (1961).

[21] S. A. Bonder, P. M. Grant, M. Stacey, and R. B. Warder, J. Chem. Soc. 2648 (1959).

[22] A. D. Grishina, Doklady, Akad. Nauk. SSSR \$50, 809 (1963).

[23] J. H. Flynn and W. L. Morrow, J. Polymer Sci. 2A, 91 (1964).

[24] M. Horio, R. Imamura and H. Mizukami, Bul. Inst. Chem. Research Kyoto Univ. 41, 17 (1963).

[25] J. Osakabe and H. Yamashita, Radioisotopes 6, 29 (1957).

[26] Z. Kuri, Y. Fujiwara, H. Ueda, and S. Shida, J. Chem. Phys. 33, 1885 (1960).

[27] M. A. Swanson and C. F. Cori, J. Biol. Chem. 172, 797 (1948).

[28] I. Levi and E. Lozinski, Canadian J. Biochem. Physiol. 33, 448 (1955).

[29] D. J. Currie and F. S. Dainton, Trans. Faraday Soc. 61, 1156 (1965).

[30] A. R. Shultz, P. J. Roth, and G. B. Rathmann, J. Polymer Sci. 27, 495 (1956).

(Paper 71Al-433) 